\title{
Major Morphophonemic Operations in Ezha [Ethio-Semitic]
}

\author{
Endalew Assefa * \\ (Addis Ababa University, Ethiopia)
}

\begin{abstract}
This article describes the various phonological/morphophonemic processes resulting from segmental co-occurrences within simple words (words which constitute a single morpheme) and at morpheme junctures of complex words in the Ezha language. The language is found to be rich in such operations. The morphophonemic processes identified and described in this study include assimilation, labialization, palatalization, depalatalization, vowel fronting, vowel deletion, deletion of a glide and a vowel, epenthesis and spirantization. Among these operations, assimilation is found to be by far the most prominent.
\end{abstract}

Keywords: assimilation, spirantization, epenthesis, depalatalization, morphophonemic

\section{Introduction}

Ezha is one of the different Gurage languages, which are spoken in the Gurage zone of the Southern Nations, Nationalities and Peoples Region (SNNPR) of Ethiopia. Ezha is typically spoken in and around the town of Agenna. The language belongs to the Southern Semitic sub-branch of the Ethio-Semitic language phylum (cf. Hetzron, 1977).

This article deals with the description of morphophonemic processes in the Ezha language. Those processes that operate both within simple words and at morphemic boundaries of complex words are dealt with. To access the required data for the study, word list elicitation supplemented by recording of free narratives was conducted in consultation with native speakers of the language.

\section{Discussion}

This section presents the description of various phonological/morphophonemic operations in the target language. These operations include assimilation, labialization, palatalization, depalatalization, vowel fronting, vowel deletion, deletion of a glide and a vowel, epenthesis and spirantization, and they are discussed one at a time as follows.

\subsection{Assimilation}

Assimilation of a phoneme to another adjacent phoneme is found to be the most

* Dr. Endalew Assefa: Assistant Professor of General Linguistics, Department of Linguistics and Philology, College of Humanities, Addis Ababa University, Ethiopia. E-mail: endexye2006@gmail.com. 


\section{Endalew Assefa}

common phenomenon in Ezha. Both partial and total assimilation are attested in the language, which can be either progressive or regressive; regressive assimilation is much more frequent (cf. Endalew, 2014). Assimilation covers different domains as discussed separately in the following sections.

\subsubsection{Homorganic nasal assimilation}

In Ezha, sounds at both the bilabial and labiodental points of articulation are found to influence a preceding adjacent alveolar $n$ so that the alveolar segment becomes more alike or identical to the affecting segments, as demonstrated in the following examples.

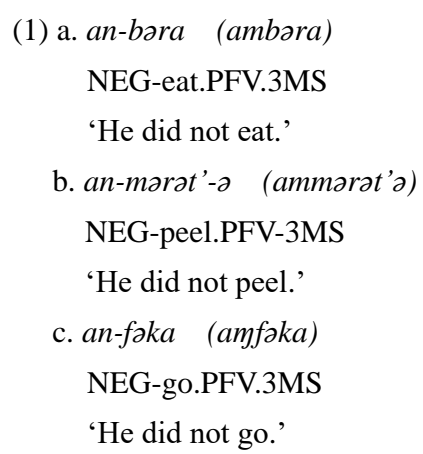

The examples in $(1 \mathrm{a} \& \mathrm{c})$ show instances of partial assimilation as the affected sound, i.e. $n$, shares some but not all of the phonetic characteristics of the affecting segments, i.e. the labials, whereas the example in (1b) depicts a total assimilation since the affected and the affecting sound become identical. The assimilation in both cases is regressive for the influencing sound occurs to the right of the influenced one; hence, the shared phonetic features regress back to the left.

One would also argue that in words like ambir 'cabbage', $[\mathrm{m}]$ is the allophone of the underlying $n$ which undergoes assimilation due to the effect of the following adjacent sound $b$. This, however, turns out to be a mere guess as both $n$ and $m$ exist within the phonemic inventory of the language; hence, $m$ could be an underlying sound in the aforementioned word. In words like amfunna 'nose' and amf" 'bird', however, it could be plausible to argue that $[\mathrm{m}]$ is the phonetic variant of the underlying $n$ since $m$ is absent from the language's phonemic inventory; it only occurs in predictable contexts where $n$ is followed by labiodentals, $f$ and $f^{v}$.

Homorganic nasal assimilation also takes place with alveopalatal consonants. When $n$ occurs adjacent to the left of alveopalatal consonants, it appears as $[n]$, a palatal element which does not exist in the language's phonemic inventory, as exemplified in the data given below.

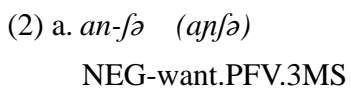




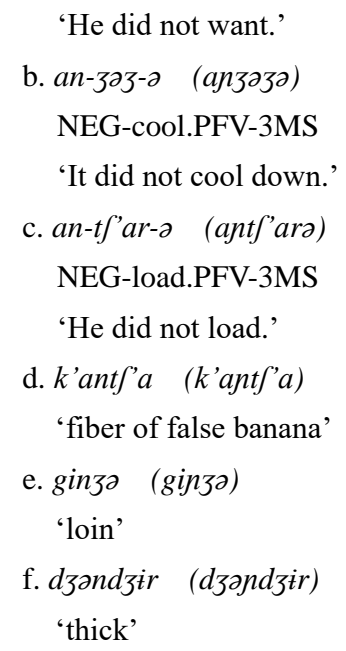

As can be seen from the examples, all the alveopalatal consonants impose their [+HIGH] feature on the immediately preceding nasal $n$. In the examples (2d-f), it is plausible to argue that $[n]$ surfaces as an allophone of the underlying $n$. This is due to the fact that $n$ is not a phoneme in Ezha; it occurs in contexts where $n$ is followed by an alveopalatal sound, hence, a predictable occurrence.

The other frequently occurring type of nasal assimilation in the Ezha language is attributed to velarization, a process whereby an originally non-velar nasal becomes a velar one due to its co-occurrence with an adjacent velar segment as in (3).

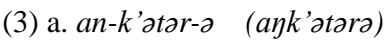

\section{NEG-kill.PFV-3MS}

'He did not kill.'

b. an-gadad-a (aๆgadada)

NEG-tear.PFV-3MS

'He did not tear.'

c. an-kataf-a (aクkatafa)

NEG-slice.PFV-3MS

'He did not slice.'

d. an-xar-a (aךxəra)

NEG-become.PFV-3MS

'It was not the case.'

e. wangeta (waygeta)

'thigh'

f. ank'a (ayk'a)

'mouth' 


\section{Endalew Assefa}

g. atankirt (ataykirt)

'tree'

In the data given above, the nasal $n$ is triggered to homorganically assimilate to the following velar segment, hence, becoming [ $\eta]$. All the velar consonants attested in Ezha motivate such a phenomenon whenever they are immediately preceded by $n$. With regard to the degree of change, this assimilation is partial since the influencing and the influenced sounds become more and more alike, but not completely identical. It is logical to argue that the underlying $n$ appears as $[\eta]$ in the examples (3e-g). This is because $\eta$ is not a phoneme in Ezha. Thus, in words like waygeta 'thigh', $y$ cannot be an underlying sound, but $n$ can.

In general, the homorganic nasal assimilation process entails that there is no consonant sequence involving the nasal $n$ immediately followed by a labial, an alveopalatal or a velar sound at the phonetic level.

\subsubsection{Total assimilation of $t$}

In the Ezha language, $a t$ - is the indirect causative morpheme. The alveolar sound $t$ of this morpheme assimilates to the following alveopalatal segment at a morpheme boundary. This phenomenon occurs whenever the causative morpheme is prefixed to verbs beginning with any of the alveopalatal consonants as shown below.

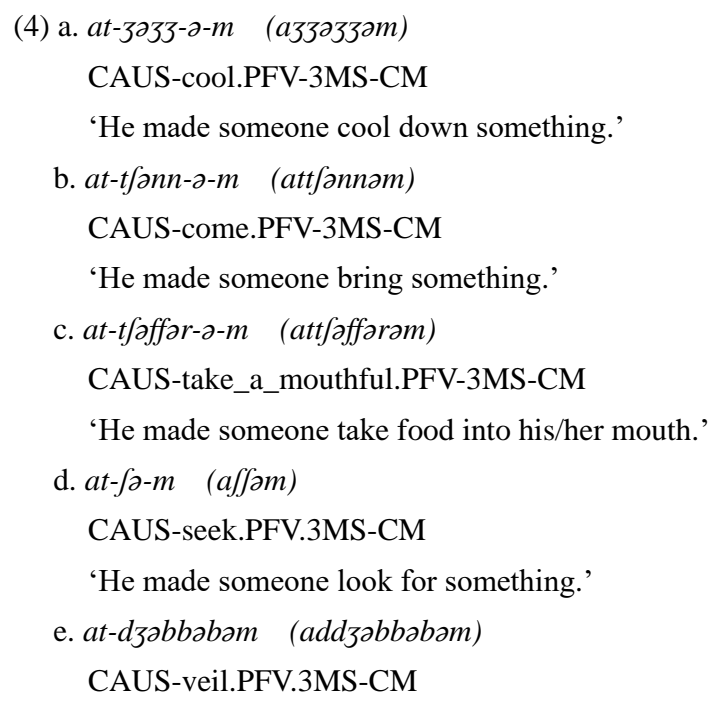

'He made someone veil something.'

In all these examples, $t$ of the causative morpheme at- undergoes a homorganic assimilation with the adjacent consonants so that it becomes [J], [3], [t]] and [dz], hence, total regressive assimilation.

$t$ of the causative morpheme at- also assimilates to a following glottalized consonant. Whenever the causative morpheme is attached to verbs beginning with an ejective, $t$ of the 
prefix becomes identical to the following ejective sound.

(5) a. at-t'วnnวg-ə-m (att'วnnวgəm)

CAUS-sweep.PFV-3MS-CM

'He made someone sweep something.'

b. at-tf'วnпว-ว-m (attf'วnпวт)

CAUS-give_birth.PFV-3MS-CM

'He made an animal give birth.'

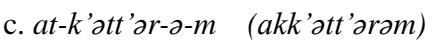

CAUS-kill.PFV-3MS-CM

'He made someone kill something.'

In these examples, $t$ occurs in the phonemic transcriptions but this sound changes to [ $\left.t^{\prime}\right]$, $\left[t f^{\prime}\right]$ or $\left[k^{\prime}\right]$ in the phonetic counterparts depending on the sound which immediately follows it. The assimilation is total regressive since the affecting sound exists to the right of the affected one, and the two sounds become identical.

$t$ undergoes another type of total assimilation which is attributed to voicing: a process whereby an originally voiceless sound turns into voiced either due to the influence imposed by a neighboring voiced segment as is the case in other Ethio-Semitic languages like Amharic (cf. Baye, 2008) or because of a particular context which triggers voicing as is the case in some languages like English (cf. Katamba, 1989). In the Ezha language, context sensitive voicing is not attested, whereas voicing of a voiceless alveolar $t$ is found to occur at a morpheme juncture upon the influence of an adjacent voiced sound. When the causative morpheme at-is prefixed to verbs beginning with the voiced alveolars $d$ and $z$, or the voiced alveopalatal 3 , the sound $t$ of the prefix totally assimilates to the consonant which begins the verbal base as demonstrated below.

(6) a. at-dənпวg-ə-m (addənnวgəm)

CAUS-hit.PFV-3MS-CM

'He made someone be hit.'

b. at-zaggar-a-m (azzaggaram)

CAUS-jump.PFV-3MS-CM

'He made someone jump.'

c. at-3ə33-ว-m (aз3วз3วकm)

CAUS-cool.PFV-3MS-CM

'He made someone cool down something.'

In all of the examples, $t$ of the causative morpheme assimilates to the first root consonant of the verb so that it changes its status in terms of vocal fold situation, hence, becoming $[d]$, [z] and [3] when it is followed by $d, z$ and 3 respectively. This process designates an instance of total regressive assimilation as the target sound becomes completely identical to 


\section{Endalew Assefa}

the affecting segment.

$t$ can also undergo an assimilation process called spirantization. This phenomenon refers to the situation by which a non-fricative sound becomes a fricative one. The process could be either a result of an influence from an adjacent fricative segment or simply context dependent. The context sensitive spirantization will be discussed separately later. To emphasize spirantization occurring as a type of assimilation, $t$ of the causative prefix atassimilates to a coronal voiceless fricative beginning a verbal base to which the prefix attaches.

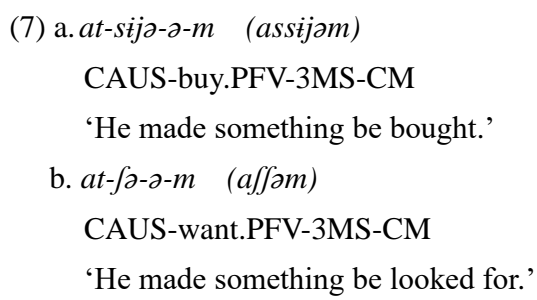

$t$ has changed to $[s]$ and $\left[\int\right]$ upon the influence of the following $s$ and $\int$ respectively. Thus, $t$ has lost its status of being a plosive and acquires another feature so that it becomes a fricative through total regressive assimilation. Note also that the same phenomenon, in addition to voicing, occurred in (6b\&c), where $t$ changes into $[z]$ and [3].

\subsubsection{Total assimilation of $r$}

In situations where $r$ is followed by $n$ at a morpheme boundary, a total regressive assimilation occurs as in the data given below.

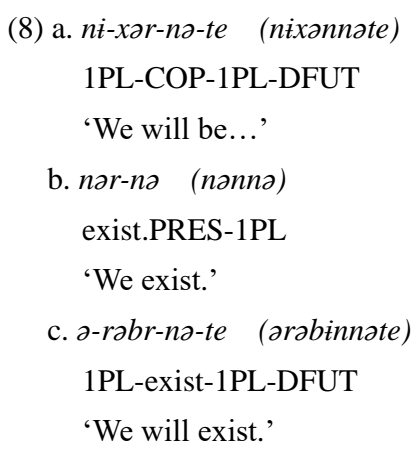

As can be noticed from the data, when the 1PL subject suffix attaches to the copular and existential verbs, the verb final $r$ surfaces as $[n]$ upon its adjacency to the alveolar nasal beginning the subject affix.

\subsubsection{Palatalization}

The high front vowel $i$ in Ezha is characterized by its strong palatalizing effect on non-palatal coronal consonants (cf. Ullendorff (1955) for a similar phenomenon in Gurage and Baye (2008) for Amharic). The vowel serves as a second person singular feminine 
marker with jussive/imperative and imperfective verbs. When this suffix is added to verbs ending with an alveolar consonant, the suffix $-i$ changes this consonant into the corresponding alveopalatal sound.

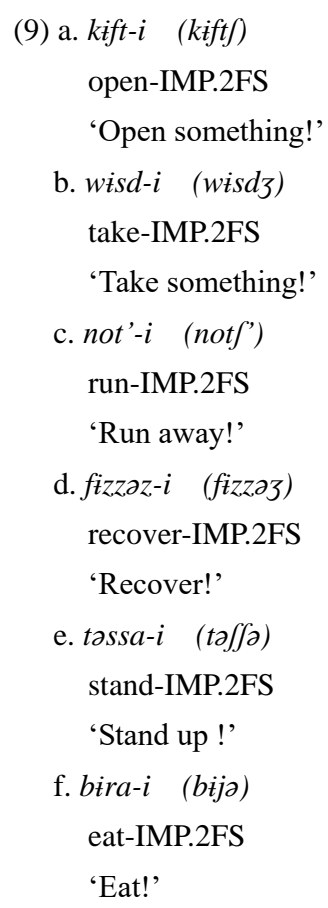

The data show that the last consonant in each of the verbs has changed from an alveolar to the corresponding alveopalatal consonant upon the influence of the $2 \mathrm{FS}$ imperative suffix $-i$. The phenomenon leads to the establishment of a clear correspondence between alveolars and their alveopalatal correlates as indicated in.

$\begin{aligned} \text { (10) } / d / & >[d 3] \\ \mid t / & >[t f] \\ \mid t \prime & >\left[t f^{\prime}\right] \\ \mid z / & >[3] \\ \mid s / & >\left[\int\right] \\ \mid r / & >[j]\end{aligned}$

The occurrence of $l, r$ and $n$ in Gurage in general and in Ezha in particular is quite unstable (cf. Ullendorff, 1955). In verbs, these sounds surface as $r$ when they are non-geminate. Thus, no verb employing the lateral $l$ and the nasal $n$ as a last root consonant in the jussive/imperative form could be attested in Ezha.

In the data given in (9), in addition to the consonantal modification, vocalic alteration may also occur. When the final root consonant is followed by a vocalic radical, as in (9e\&f), 


\section{Endalew Assefa}

apart from the palatalization of the root consonant, the word-final vocal radical is altered.

Velar consonants can also be influenced by the suffix $-i$ if they occur at the end of a jussive/imperative verb to which $-i$ is attached. In situations where $-i$ is suffixed to verbs ending with a consonant other than an alveolar and a velar, the effect of the suffix spreads further to the left and palatalizes the nearest possible palatalizable consonant and/or triggers fronting of a vowel within the verbal base.

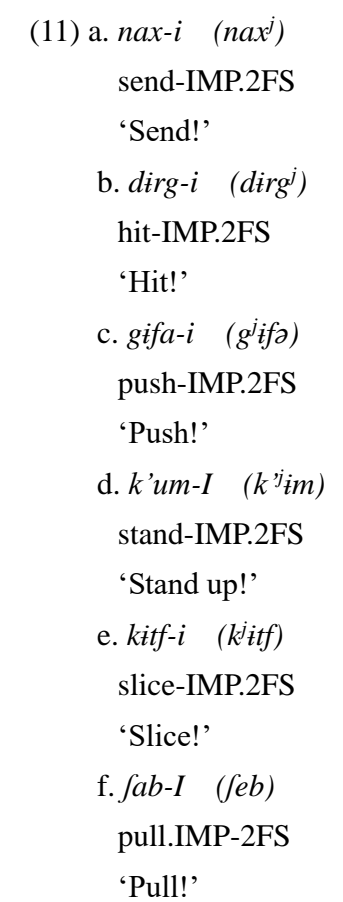

In the examples (11a\&b), the terminal consonants of the verb are palatalized, whereas in (11c-e), the effect of the suffix $-i$ floats further to the left in looking for a palatalizable consonant and lands on the verb initial velars as the terminal consonants are not eligible for palatalization. In (11f), unlike (11a-e), since there is no palatalizable consonant within the verbal base, the palatalizing effect of the suffix $-i$ lands on the vowel $a$ thereby initiating vowel fronting: the central $a$ changes to the front $e$. Notice also the vocalic alternations in addition to palatalization in $(11 \mathrm{c} \& \mathrm{~d})$.

Palatalization is also attested to occur in situations where the suffix $-j a$ is attached to jussive/imperative verbal bases to derive result nouns as in the following examples.
(12) a. tfut- 'plough (V)'
tfut-ja (tfuttfa) 'farm (N)'
b. $n u t$ '- 'run (V)'
nut'-ja (nuttf'a) 'run (N)'

The derivational process in (12) involves both regressive and progressive assimilation types operating one after the other. First, the base final consonants are changed into their 
corresponding alveopalatal correlates due to the effect of the $[+\mathrm{HIGH}]$ consonant at the beginning of the derivational morpheme. Once the $[+\mathrm{HIGH}]$ consonant spreads its feature to the preceding alveolar consonant, the resultant consonant in turn progressively influences the consonant at the onset of the suffix. Thus, the two sounds become identical at the surface level.

\subsection{Labialization}

Labialization refers to the phonological process by which a non-rounded sound gets a [+ROUND] feature upon the influence of a certain context. In the Ezha language, non-coronal consonants (labials and velars) other than $w$ are affected by the operation; the glide $w$ is not affected by this phenomenon for it inherently possesses the feature in question. The process occurs in two situations. The first scenario is when constructing impersonal (passive) expressions. In impersonal expressions, the subject is marked by non-segmental features yielding labialization and palatalization of root consonants. The following are examples of labialization.

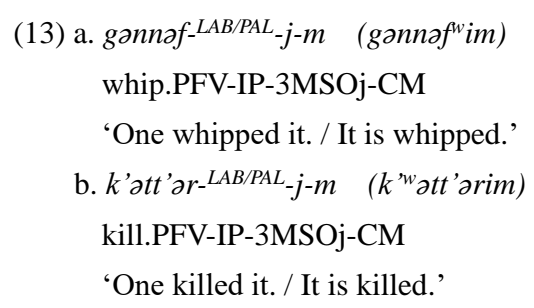

As can be observed from the data, the non-segmental labial feature affects labials and velars. If the rightmost root consonant is labializable, the feature ends up there as in (13a); if such a root consonant cannot be labialized, however, the feature further spreads to the left until it gets a labializable consonant where it can land as in (13b). Thus, the plain consonants $f$ and $k^{\prime}$ become $\left[f^{w}\right]$ and $\left[k^{\text {ww}}\right]$ in their respective order after the labialization process.

The second situation where labialization occurs relates to 3MS object marking. Whenever a verb is co-marked by a $3 \mathrm{MSOj}$ suffix and a singular subject affix except for the $2 \mathrm{FS}$ subject, the rightmost non-coronal root consonant undergoes labialization as demonstrated in (14).
(14) a. fabəm 'He pulled.'
fabənim (Jab ${ }^{w}$ ənim) 'He pulled him.'
b. Sabott/fm 'She pulled.'
Sabottfinim (fab ${ }^{w}$ ottfinim) 'She pulled him.'
c. $k$ 'att' $\partial r x^{w}$ im 'I killed.'
k'att'arx'tinim (k'att'arx ${ }^{w}$ inim) 'I killed him.'

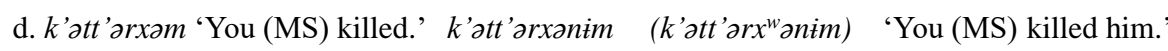

There is no labialization operating on the verbs which are not marked for 3MSOj. The operation only applies when the verbs bear the $3 \mathrm{MSOj}$ suffix, i.e., $-n$. The triggering factor for the process to occur can be attributed to a non-segmental feature, i.e. $L A B$ that 


\section{Endalew Assefa}

accompanies the light ${ }^{\mathbb{1}} 3 \mathrm{MS}$ object suffix. In (14d), it is not a root consonant which undergoes labialization; since the consonant within the subject affix, - $x$ ə, is labializable, it attracts the feature in question so that the non-coronal root consonant remains unaffected by the process. In (14c), on the other hand, the $1 \mathrm{~S}$ subject suffix is inherently labialized as it is observable from the verb which is not marked for $3 \mathrm{MSOj}$. Thus, there is no need to apply the operation for such conjugations.

\subsection{Non-assimilative palatalization}

Apart from an assimilative palatalization discussed earlier, non-assimilative palatalization is also attested to operate in Ezha. This palatalization type is not attributed to segmental co-occurrences (hence, the term non-assimilative) and is found to occur in impersonal expressions. In this case, the non-segmental feature which marks the impersonal subject yields palatalization of a root consonant as in the following example.

(15) mannət'-LAB/PAL $-j-m \quad$ (mwnote'im)

peel.PFV-IP-3MSOj-CM

'One peeled it. / It is peeled'

As can be noticed from the example, palatalization influences alveolars. In this particular example, the non-segmental impersonal subject marking feature yields both labialization and palatalization of root consonants. As for the palatalization, $t$ ' is changed to [t ${ }^{\prime}$ '] upon the influence of the aforementioned feature.

\subsection{Depalatalization}

Some alveopalatal sounds at the beginning of verbs depalatalize and turn out to surface as an alveolar when a prefix is attached to the verbal bases. This phenomenon is illustrated below by using the negative prefix an- in 3MS negative expressions whereby the base initial sounds $t \int$ and $d z$ change to $[t]$ and $[d]$ respectively.

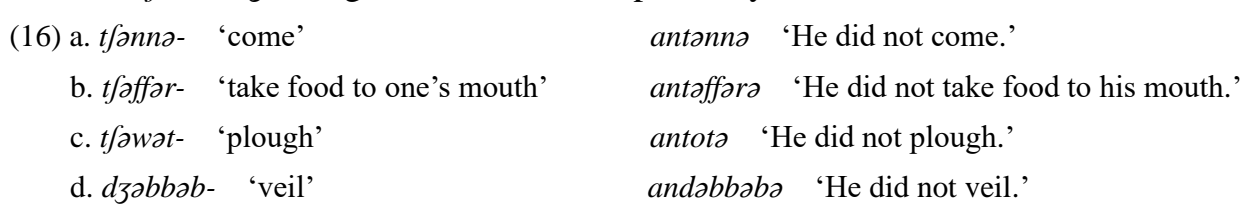

One would possibly argue that the depalatalization is attributed to progressive assimilation. The alveolar consonant $n$ at the end of the negative prefix seems to have shared its place feature to the stem initial post-alveolar affiricates $t \int$ and $d_{3}$ thereby initiating the affricates to change to the corresponding alveolar sounds, $[t]$ and $[d]$.

\subsection{Vowel fronting}

In Ezha, whenever the negative prefix $a$ - is attached to verbs in the 3MS or 3PL imperfective and jussive conjugations which start with the person prefix $j$-, the negative

\footnotetext{
(1) Light object affixes are those which presuppose a singular subject affix except for the 2FS.
} 
prefix $a$ - changes to the front vowel $[e]$. The phenomenon occurs due to the effect of the person prefix $j$ - as illustrated in the following examples.

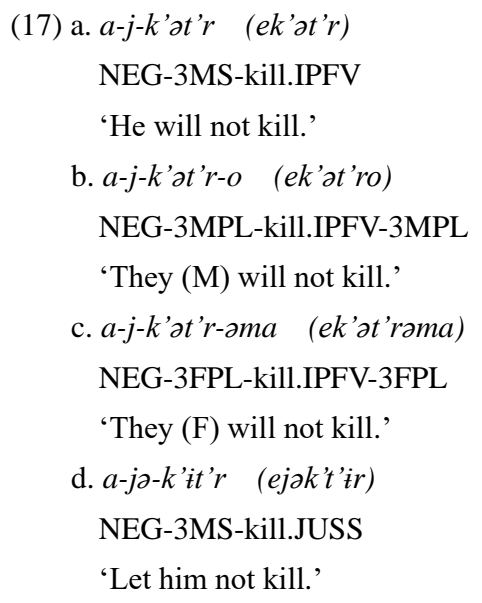

In the imperfective conjugations, having initiated the negative prefix to undergo fronting, the person prefix eventually elides as in (17a-c), hence, it becomes vacuous in the surface representations. In (17d), the person prefix $j \partial$ - is not deleted; this seems due to the need to preserve the language's phonotactics by way of avoiding an impermissible vowel cluster. There are also other instances where the person prefix remains in situ. This occurs when the negative prefix attaches to imperfective verbs beginning with a vowel as in the following example.
(18) a-j-adir (ejadir)
NEG-3MS-spend_the_night.IPFV
'He will not spend the night.'

The fact that the person prefix $j$ - remains in place is arguably attributed to the language's phonotactics; its absence results in a vowel cluster which is impermissible in the language.

Vowel fronting also occurs when the $1 \mathrm{SOj}$ or $3 \mathrm{MSOj}$ suffix $-j$ is attached to a verb with the vowel a word-finally, as in the following examples, in which the vowel a belongs to the subject agreement markers with perfective verbs.

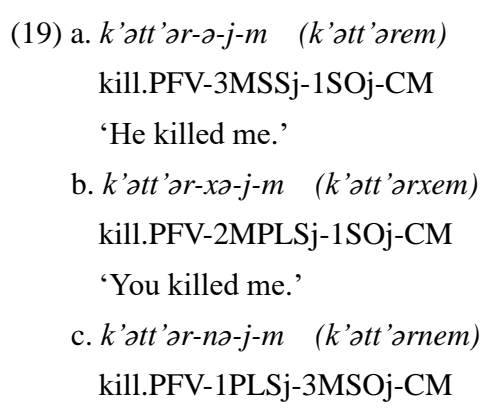




\section{Endalew Assefa}

'We killed him.'

The 3MS subject suffix - $a$ in (19a) and $a$ of the 2MPL and 1PL subject affixes in (19b\&c) change to $[e]$ due to the immediate adjacency with $-j$; note also the omission of $-j$ after the fronting operation in all of the examples.

Finally, vowel fronting occurs due to the effect of the suffix $-i$ which marks 2FS in the imperative conjugations as in the following examples whereby $u$ changes to $i$ in (20a) and $a$ changes to $e$ in (20b). We may call both operations as vowel harmony or distant assimilation.

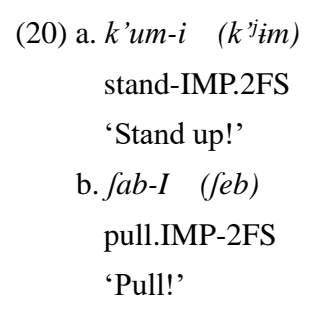

\subsection{Vowel deletion}

Ezha does not tolerate vowel clustering. When two vowels appear in a sequence at a morpheme boundary, the impermissible cluster must be broken up either by an epenthetic glide or by dropping one of the vowels. Glide insertion will be discussed later; in this section, the focus is only on instances whereby undesirable vowel clustering is adjusted by vocalic elision.

Whenever a prefix ending in a vowel is attached to a word beginning with the same or a different vowel, the vowel in the prefix is deleted. This is illustrated by the following data which employ the genitive and instrumental markers jo- and bo-respectively.

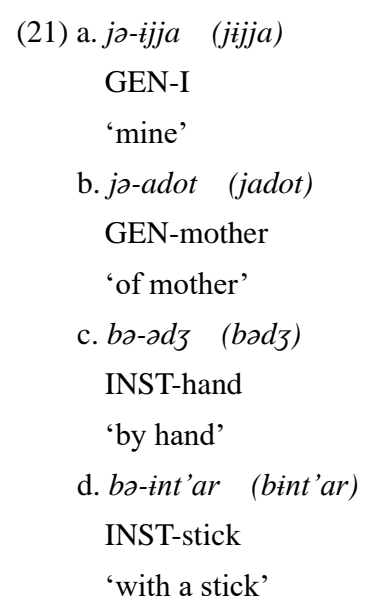

The mid central vowel $a$ is susceptible to omission whenever it is followed by another vowel of a different quality as in the examples (21a-b\&d) or a vowel of the same quality as 
in the example (21c).

Vowel deletion also occurs when the vocative suffix $-o$ is attached to nouns ending in a vowel as in the following examples.

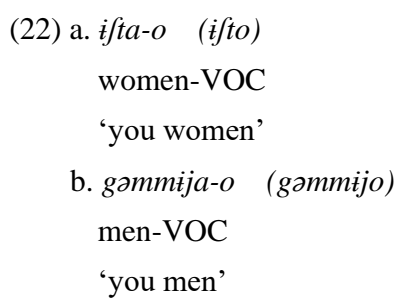

In these examples, the terminal vowel $a$ of the nouns is elided when it is followed by the vocative suffix $-o$. Based on the data in (21) and (22), we can deduce that if vowel deletion occurs, it is the preceding vowel in the sequence which is omitted.

\subsection{Deletion of a glide and a vowel}

The morpheme $a$ - marks direct causation in Ezha. In situations where this prefix is attached to verbs with a labio-velar glide $w$ at the onset followed by the vowel $\partial$, the vowel together with the preceding glide gets dropped in the manner shown below.
(23) a. watt' $a$ - 'climb'
$a$-wott' $a-\quad$ (att'a-) 'bring up'
b. wand- 'get down'
a-wand- (and-) 'bring down'

It sounds plausible to argue that first the glide is elided, though there is no apparent phonological reason to trigger the operation, and then, since the language's phonotactics does not allow vocalic clustering, the vowel following the base initial glide is omitted leaving the space for the causative prefix $a$-.

\subsection{Epenthesis}

Ezha employs two types of epenthesis: vowel insertion and glide insertion, both of which are dictated by the phonotactics of the language.

\subsubsection{Vowel insertion}

In Ezha, a maximum of two-member consonant clusters is permissible at word-medial and final positions. In situations where two consonants at a word-initial position (other than $r$ as a second member of the cluster) or more than two consonants at word-medial and final positions co-occur, the epenthetic vowel $[\dot{i}]$ is inserted between the consonants so that the undesirable clusters can be dissolved.

$$
\begin{array}{rll}
\text { (24) a. } \text { mdad } & \text { (midad) } & \text { 'clay plate' } \\
\text { b. fjjak' } & \text { (fijjak') } & \text { 'goat' } \\
\text { c. waxtta } & \text { (waxitta) } & \text { 'root of a false banana' } \\
\text { d. } \text { k'unzz }^{\prime} \text { (k'unziz) } & \text { 'anus' }
\end{array}
$$

The examples $(24 a \& b)$ depict that the epenthetic vowel is inserted to adjust an impermissible word-initial consonant cluster, whereas the examples $(24 \mathrm{c} \& d)$ demonstrate 


\section{Endalew Assefa}

the situation whereby [i] breaks up undesirable word-medial and word-final consonant clusters.

The epenthetic vowel can also be used to adjust a disallowed consonant cluster at morpheme boundaries. This occurs when a suffix with a geminated consonant at the initial is attached to a word ending with a consonant as in (25a-c) or when a suffix with a single initial consonant is attached to a word ending with two consonants (a cluster of consonants or a geminate consonant) as in ( $25 \mathrm{~d} \& \mathrm{e})$.

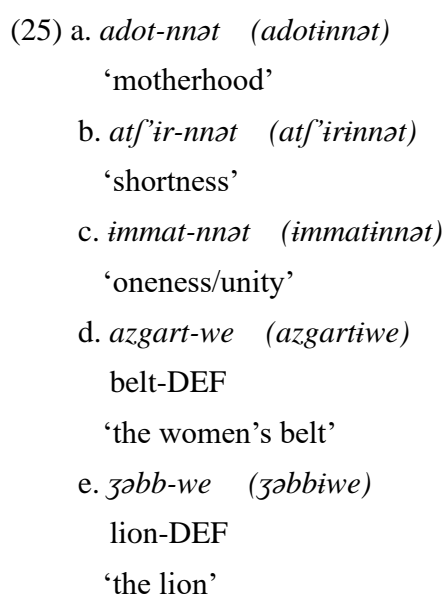

\subsubsection{Glide insertion}

As Ezha does not allow two or more vowels to occur in sequence, if a suffix with an initial vowel is attached to a word with a terminal vowel, either of the two glides, [w] or $[j]$, is inserted between the consecutive vowels so that the impermissible vowel cluster can be adjusted. This applies in situations where vowel deletion does not occur as demonstrated below.

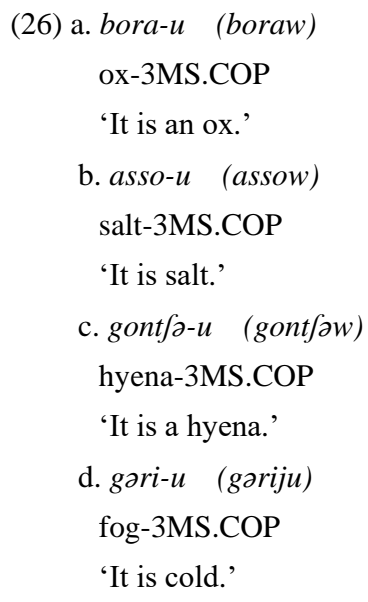




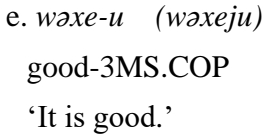

When the word ends in a non-front vowel, the labiovelar glide $[w]$ is inserted to break up the co-occurrence of two vowels as in the examples (26a-c). These examples depict that once the epenthetic glide is inserted, the copular suffix becomes phonetically invisible. This happens evidently because the labiovelar glide has closely related articulatory characteristics with the vowel $u$ so that their co-occurrence results in a swallowed pronunciation of $u$ by $w$. The fact that $[w]$ is inserted in such contexts can be further

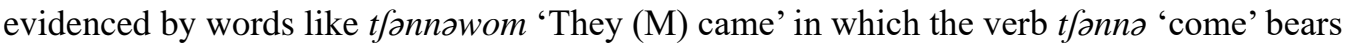
the 3MPL subject suffix $-o$ and the epenthetic glide breaks up the vowel cluster resulting from the co-occurrence of the verb final vowel $a$ and the aforementioned subject suffix. By contrast, if the terminal vowel of the word hosting a vocalic suffix is a front vowel, it is the palatal glide $[j]$ which plays the role of breaking up the vowel sequence as in the examples (26d\&e).

\subsection{Spirantization/fricativization}

Spirantization is a phenomenon by which a non-continuant obstruent segment is phonetically realized as a fricative due to a particular phonological context. Non-geminate $b$ in Ezha is found to appear as $[\beta]$ when it occurs in post-vocalic and inter-vocalic settings as exemplified below.

$$
\begin{aligned}
& \text { (27) a. } x^{w} \partial x^{w} \partial b \quad\left(x^{w} \partial x^{w} \partial \beta\right) \quad \text { 'star' } \\
& \text { b. wazgab (wazgəß) 'door' } \\
& \text { c. } s \partial b \quad(s \partial \beta) \quad \text { 'man' } \\
& \text { d. toba (to } \beta a) \text { 'Muslim' } \\
& \text { e. abar (aßar) 'sunny season' }
\end{aligned}
$$

The examples (27a-c) depict that the phoneme $b$ phonetically occurs as $[\beta]$ in post-vocalic positions, while the examples $(27 \mathrm{~d} \&$ e) illustrate the situation whereby an inter-vocalic context motivates the same phonological process. In some Gurage languages, $\beta$ is taken as a phoneme (cf. Hetzron, 1977; Degif, 2000; Meyer, 2011), which, however, is not the case in Ezha.

\section{Summary}

This article is meant to provide a description of the morphophonemic processes operating in the Ezha language. It is revealed that the language exhibits various morphophonemic processes which include assimilation, labialization, palatalization, depalatalization, vowel fronting, vowel deletion, deletion of a glide and a vowel, epenthesis and spirantization. Assimilation is the most productive operation in the language. In terms 


\section{Endalew Assefa}

of directionality, the overwhelming majority of assimilative processes are found to be regressive, progressive assimilation being quite rare. With reference to the degree of change, on the other hand, both partial and total assimilation productively operate in the language. Vowel deletion and glide insertion are complementary processes which happen to regulate impermissible vocalic clustering. Generally, the majority of the processes occur at morphemic boundaries of complex words; processes which assume simple words are found to be very limited.

\section{Symbols and abbreviations}

Note: The abbreviations for person, number and gender as well as "Sj" and "Oj" often occur in combinations.

$\begin{array}{llll}/ / & \text { Phonemic } & \text { IPFV } & \text { Imperfective } \\ {[]} & \text { Phonetic } & \text { JUSS } & \text { Jussive } \\ 1 & \text { First person } & \text { LAB } & \text { Labialized } \\ 2 & \text { Second person } & \mathrm{M} & \text { Masculine } \\ 3 & \text { Third person } & \mathrm{N} & \text { Noun } \\ \text { CAUS } & \text { Causative } & \text { NEG } & \text { Negative } \\ \text { CM } & \text { Clause Marker } & \text { Oj } & \text { Object } \\ \text { COP } & \text { Copula } & \text { PAL } & \text { Palatalized } \\ \text { DEF } & \text { Definite } & \text { PFV } & \text { Perfective } \\ \text { DFUT } & \text { Definite Future } & \text { PL } & \text { Plural } \\ \text { F } & \text { Feminine } & \text { PRES } & \text { Present } \\ \text { GEN } & \text { Genitive } & \text { S } & \text { Singular } \\ \text { IMP } & \text { Imperative } & \text { Sj } & \text { Subject } \\ \text { INST } & \text { Instrumental } & \text { V } & \text { Verb } \\ \text { IP } & \text { Impersonal } & \text { VOC } & \text { Vocative }\end{array}$

\section{References}

Assefa, E. 2014. Descriptive Grammar of Ezha: A Central West Gurage Language, Ethio-Semitic [D]. $\mathrm{PhD}$ dissertation, Addis Ababa University, Addis Ababa.

Baye, Y. 2008. Amharic Grammar [M]. Addis Ababa: Eleni Private Limited Press.

Degif, P. 2000. Sound Mutation. The Morphology of Chaha [M]. Philadelphia \& Amsterdam: Benjamins. Hetzron, R. 1977. The Gunnän Gurage Languages [M]. Naples: Istituto Orientale di Napoli.

Katamba, F. 1989. An Introduction to Phonology [M]. London \& New York: Longman.

Meyer, R. 2011. Gurage [A]. In S. Weninger (ed.), The Semitic Languages: An International Handbook [C]. De Gruyter Mouton, 1220-1275.

Ullendorff, E. 1955. The Semitic Languages of Ethiopia: A Comparative Phonology [M]. London: Taylor's. 